\title{
FAKTOR-FAKTOR YANG MEMPENGARUHI TINGKAT STRES PADA ANAK USIA SEKOLAH DASAR YANG SIBUK DAN TIDAK SIBUK
}

\author{
Affected Factors of Stress Level in Busy and Unbusy School Age Children \\ DIAH KRISNATUTI PRANADJI ${ }^{1 *}$, NURLAELA $^{2}$ \\ ${ }^{1}$ Staf Pengajar Departemen Ilmu Keluarga dan Konsumen, Fakultas Ekologi \\ Manusia, Institut Pertanian Bogor, Jalan Lingkar Kampus IPB Dramaga, \\ Bogor 16680 \\ ${ }^{2}$ Program Studi Gizi Masyarakat dan Sumberdaya Keluarga, Fakultas Pertanian, \\ Institut Pertanian Bogor, Kampus Dramaga, Bogor 16680
}

\begin{abstract}
The purpose of this study was to examine factors that influenced stress degree in busy and unbusy children of elementary school. The research conducted in SD Bina Insani Bogor. The research method was cross sectional study with 30 samples of busy children and 30 samples of unbusy children. The site of the research was selected purposively by considering that SD Bina Insani Bogor is one of the favorite private schools in Bogor. Moreover, SD Bina Insani Bogor has tight schedule and also has a large numbers of students who participated in extracurricular activities/activities after school program. The results showed that there were significant differentiation between busy children and unbusy children in time allocation and amount of extracurricular activities/activities after school program. Female students allocated more time I extracurricular activities after school than male students. Amount of extracurricular activities/activities after school, its time allocation, and time allocation for watching TV were factors that affected stress level of the children. Finally, factors affected the degree of stress of students were the amount of extracurricular activities after school, and the time allocation for watching TV.
\end{abstract}

\section{Key words: busy children, elementary school, unbusy children, stress degree}

\section{PENDAHULUAN}

Dua puluh tahun yang lalu, ahli psikologi Amerika, Elkind memperkenalkan sebuah istilah baru yakni hurried children untuk menggambarkan fenomena anak yang dipercepat perkembangannya. Salah satu cirinya adalah anak diberi berbagai aktivitas ekstrakurikuler setiap minggu yang bertujuan untuk meningkatkan kemampuan di bidang akademik, sosial, olahraga, budaya dan kemampuan psikologi. Berbagai aktivitas tersebut dilakukan di bawah pengawasan orang tua sehingga bukan sekedar untuk bersenang-senang, namun lebih diarahkan pada pencapaian tujuan (Gross tt).

Menurut Hurlock (2002), anak usia sekolah dasar diharapkan memperoleh dasar-dasar pengetahuan yang dianggap penting untuk keberhasilan penyesuaian diri dalam kehidupan dan mempelajari berbagai ketrampilan penting tertentu baik ketrampilan kurikuler maupun ekstrakurikuler. Meskipun demikian, sebaiknya kegiatan tersebut tidak terlalu banyak dan membebani anak serta dilakukan berdasarkan kemauan anak dan bukan tekanan dari orang tua.

Menurut Alvin (2007), anak-anak masa kini menghadapi apa yang seharusnya menjadi masalah orang dewasa lebih dini dalam kehidupannya. Tidak seperti anak-anak di generasi lalu yang memiliki banyak waktu untuk bermain setelah pulang sekolah bersama dengan teman-temannya, anak-anak sekarang sulit untuk mendapatkan waktu seperti itu. Sekitar 60,0\% anak-anak di Jabodetabek lebih banyak menghabiskan 
waktunya dengan mengikuti kegiatan les sepulang dari sekolah (Imam 2007).

Salah satu fenomena menarik ialah semakin mudanya usia penderita stres. Jika beberapa tahun yang lalu, stres lebih banyak dialami oleh usia produktif diatas 20 tahun, kini stres banyak diderita oleh anak usia remaja, bahkan dalam beberapa kasus, anak-anak diperkirakan telah mengalami stres.

Fenomena tersebut menegaskan mengenai pentingnya mempelajari tingkat stres pada anak usia sekolah dasar yang sibuk dan tidak sibuk. Apakah meningkatnya aktivitas di luar sekolah dan berkurangnya alokasi waktu untuk bermain mempengaruhi tingkat stres anak? Bagaimanakah pengaruh faktor internal (persepsi anak, umur saat masuk sekolah dasar, serta jenis kelamin) dan faktor eksternal (persepsi ibu dan keadaan sosial ekonomi keluarga) terhadap stres pada anak? Hal inilah yang diantaranya melandasi pentingnya dilakukan penelitan yang mempelajari tingkat stres pada anak sibuk dan faktorfaktor yang mempengaruhinya.

\section{METODE}

Desain, Tempat, dan Waktu Penelitian Penelitian ini menggunakan desain cross sectional study, yakni penelitian dilaksanakan pada satu waktu tertentu. Penentuan lokasi penelitian menggunakan metode purposive, yaitu dengan pertimbangan bahwa sekolah merupakan sekolah dasar swasta favorit yang memiliki jadwal yang padat dan jumlah anak yang memiliki aktivitas di luar sekolah cukup tinggi, sehingga terpilih SD Bina Insani Bogor. Pengambilan data dilaksanakan pada bulan April hingga Agustus 2008.

\section{Contoh dan Cara Penarikan Contoh}

Contoh pada penelitian ini adalah anak kelas 5 Sekolah Dasar (SD), dengan pertimbangan anak memiliki waktu yang lebih banyak untuk melakukan kegiatan di luar sekolah (les/kursus/bimbingan/klub olahraga). Jumlah siswa kelas 5 SD Bina Insani adalah sebanyak 119 anak. Pada tahap awal pemilihan contoh, dilakukan proses penyaringan siswa melalui penyebaran kuesioner tentang jenis dan alokasi waktu aktivitas di luar sekolah yang dilakukan dalam satu minggu. Dari proses penyaringan tersebut, ternyata hanya 99 siswa yang mengisi kuisioner dengan benar dan lengkap. Selanjutnya 99 siswa tersebut diurutkan berdasarkan jenis dan alokasi waktu kegiatan di luar sekolah yang dilakukan.

Contoh anak sibuk dipilih berdasarkan urutan 30 teratas untuk alokasi waktu kegiatan di luar sekolah sedangkan contoh anak tidak sibuk dipilih berdasarkan urutan 30 terendah. Dari data tersebut, diperoleh kriteria anak sibuk adalah anak yang memiliki alokasi waktu aktivitas di luar sekolah $\geq 7$ jam setiap minggu dan anak tidak sibuk adalah anak yang memiliki alokasi waktu aktivitas di luar sekolah $\leq 3$ jam setiap minggu. Total contoh dalam penelitian ini adalah sebanyak 60 anak.

\section{Jenis dan Pengumpulan Data}

Data yang digunakan dalam penelitian ini berupa data primer dan data sekunder. Data primer meliputi data karakteristik anak (umur saat masuk SD dan jenis kelamin anak), karakteristik keluarga (besar keluarga, usia orang tua, pendapatan, dan pendidikan orang tua), persepsi anak dan ibu terhadap aktivitas di luar sekolah dan harapan orang tua, aktivitas dan alokasi waktu kegiatan di luar sekolah anak, serta tingkat stres pada anak. Data primer tersebut diperoleh melalui record pada anak dan wawancara. Data sekunder dalam penelitian ini mencakup gambaran umum lokasi penelitian. Data sekunder diperoleh dari keterangan pihak sekolah dan buku komunikasi SD Bina Insani.

\section{Pengolahan dan Analisis Data}

Data yang telah diperoleh kemudian diolah melalui proses pengecekan, coding, dan scoring. Pada mulanya data dari kuesioner ditransfer ke dalam Microsoft Excel, selanjutnya dianalisis menggunakan SPSS 13.0 for windows. Analisis data yang dilakukan meliputi statistika deskriptif (modus, mean, minimum, maksimum) dan inferensia (uji beda, korelasi, dan regresi).

\section{HASIL DAN PEMBAHASAN}

\section{Karakteristik Contoh}

Lebih dari separuh (60\%) contoh anak sibuk berjenis kelamin perempuan. $\mathrm{Hal}$ ini sangat berlawanan dengan anak 
tidak sibuk, yakni sebagian besar $(76,7 \%)$ contoh berjenis kelamin laki-laki.

Sebanyak $40 \%$ anak sibuk dan $36,7 \%$ anak tidak sibuk masuk sekolah dasar ketika berumur kurang dari 6 tahun.

\section{Karakteristik Keluarga Contoh}

Jumlah anggota keluarga contoh berkisar antara 3 hingga 6 orang. Persentase terbesar $(53,3 \%)$ contoh anak sibuk memiliki besar keluarga sedang, sedangkan persentase terbesar contoh $(53,3 \%)$ anak tidak sibuk memiliki besar keluarga kecil. Tidak terdapat contoh yang memiliki jumlah anggota keluarga z7orang. Uji beda t-test tidak menunjukkan adanya perbedaan $(p>0,05)$ besar keluarga di kedua kelompok contoh.

Usia orang tua yang diamati dalam penelitian ini dibedakan menjadi usia orang tua saat ini dan usia pada saat anak pertama lahir. Usia ayah contoh saat ini berkisar antara 34 hingga 52 tahun. Lebih dari separuh contoh anak sibuk $(73,3 \%)$ dan sebagian besar contoh anak tidak sibuk (80\%) memiliki ayah dengan kategori usia dewasa madya (4165 tahun). Tidak terdapat contoh yang memiliki ayah dengan kategori usia dewasa akhir. Rata-rata ayah contoh pada kedua kelompok berusia 44,1 tahun. Hasil uji beda t-test menunjukkan tidak adanya perbedaan $(p>0,05)$ usia ayah saat ini di kedua kelompok contoh.

Usia ibu contoh saat ini berkisar antara 31 hingga 50 tahun. Persentase terbesar usia ibu pada kedua kelompok $(56,7 \%)$ berada dalam kategori dewasa madya (41-65 tahun). Tidak terdapat ibu contoh yang berada dalam kategori usia dewasa akhir. Rata-rata ibu contoh pada kedua kelompok berusia 41,2 tahun. Uji beda $t$-test menunjukkan tidak adanya perbedaan $(p>0,05)$ pada variabel usia ibu saat ini di kedua kelompok contoh.

Sementara itu, usia orang tua saat anak pertama lahir dikategorikan menjadi 3 yaitu usia 20-30, 31-40 dan 41-50 tahun. Persentase terbesar ayah contoh anak sibuk $(76,7 \%)$ dan anak tidak sibuk $(70 \%)$ saat anak pertama lahir berusia antara 20 hingga 30 tahun. Sebesar $23,4 \%$ ayah contoh pada anak sibuk dan $26,6 \%$ ayah dari anak tidak sibuk berusia 31 hingga 40 tahun saat anak pertama lahir. Bahkan terdapat 3,3\% ayah dari anak tidak sibuk berusia antara 41 hingga
50 tahun saat anak pertama lahir. Ratarata ayah contoh berusia 29,6 tahun ketika anak pertama lahir. Hasil uji beda $t$ test menunjukkan tidak adanya perbedaan di kedua kelompok pada variabel usia ayah saat anak pertama lahir.

Sama halnya dengan persentase terbesar usia ayah saat anak pertama lahir yakni berada dalam kategori usia 20 hingga 30 tahun, demikian juga dengan persentase terbesar usia ibu saat anak pertama lahir (86,6\%). Rata-rata ibu contoh berusia 26,7 tahun ketika anak pertama lahir. Sebesar $11,7 \%$ ibu contoh pada anak sibuk berusia 31 hingga 40 tahun ketika anak pertama lahir. Hasil uji beda $t$-test menunjukkan tidak adanya perbedaan pada variabel usia ibu saat anak pertama lahir di kedua kelompok contoh.

Pendidikan Orang Tua. Pendidikan orang tua yang dimaksud dalam penelitian ini adalah jenjang pendidikan formal yang telah diselesaikan oleh orang tua contoh. Sebagian besar $(93,3 \%)$ ayah contoh dan sebagian besar $(86,7 \%)$ ibu contoh telah menamatkan pendidikan hingga Perguruan Tinggi. Uji beda Mann Whitney menunjukkan tidak adanya perbedaan $(p>0,05)$ pendidikan orang tua pada anak sibuk dan tidak sibuk.

Pekerjaan Utama. Persentase terbesar ayah contoh yakni 43,3\% pada anak sibuk dan 53,3\% pada anak tidak sibuk, memiliki pekerjaan utama sebagai pegawai swasta. Hanya terdapat 3 orang ayah anak sibuk dan 2 orang ayah dari anak tidak sibuk yang memiliki pekerjaan tambahan, yakni sebagai pegawai swasta dan wiraswasta. Lebih dari separuh ibu contoh pada kedua kelompok (60\% pada anak sibuk dan $63,3 \%$ pada anak tidak sibuk) adalah ibu bekerja. Meskipun demikian, hasil uji beda Mann Whitney menunjukkan tidak adanya perbedaan pekerjaan utama ayah $(p>0,05)$ dan pada pekerjaan utama ibu $(p>0,05)$ diantara kedua kelompok contoh.

Pendapatan Orang Tua. Hasil penelitian menunjukkan tidak terdapat pendapatan total per bulan ayah pada kelompok anak sibuk yang berada dalam kisaran kurang dari Rp 2.500.000,00. Meskipun demikian, persentase terbesar pendapatan total per bulan ayah contoh pada kelompok anak tidak sibuk $(33,3 \%)$ berada dalam kisaran lebih dari 
Rp 10.000.000,00, dan persentase terbesar $(30 \%)$ pendapatan total per bulan ayah pada kelompok anak sibuk berada dalam kisaran yang lebih rendah, yaitu Rp 7.500.001,00 sampai Rp 10.000.000,00. Hasil uji beda MannWhitney menunjukkan tidak adanya perbedaan antara pendapatan total per bulan ayah pada kedua kelompok.

Ayah contoh yang hanya berpendapatan kurang dari Rp 2.500.000,00 biasanya memiliki istri yang bekerja. Persentase terbesar ibu pada kelompok anak sibuk $(46,7 \%)$, memiliki pendapatan antara Rp 2.500.000,00 hingga Rp 5.000.000,00, sedangkan pada kelompok anak tidak sibuk, persentase terbesar ibu contoh $(40 \%)$ tidak memiliki pendapatan sendiri. Hasil uji beda Mann Whitney menunjukkan tidak adanya perbedaan $(p>0,05)$ antara pendapatan ibu pada kedua kelompok.

\section{Alokasi Waktu Contoh}

Alokasi waktu contoh anak sibuk untuk kegiatan di luar sekolah adalah sebesar 1,1 jam (67 menit) tiap harinya (sebesar 4,7\% alokasi waktu dalam sehari), sedangkan alokasi waktu anak tidak sibuk lebih rendah, yaitu sebesar 0,3 jam (18 menit). Hasil uji beda t-test menunjukkan adanya perbedaan yang sangat nyata $(p<0,01)$ pada variabel alokasi waktu contoh untuk kegiatan di luar sekolah.

\section{Aktivitas di Luar Sekolah}

Aktivitas di luar sekolah yang banyak dilakukan oleh contoh adalah les mata pelajaran, les privat, mengaji, les musik, les kumon, dan klub olahraga (bulutangkis dan renang). Jumlah aktivitas anak tidak sibuk berkisar antara 0 (tidak memiliki aktivitas di luar sekolah) hingga 3 aktivitas dalam satu minggu, sedangkan anak sibuk memiliki jumlah aktivitas antara 1 hingga 5 jenis aktivitas di luar sekolah. Setiap jenis aktivitas memerlukan waktu antara 0,5 hingga 3 jam.

Persentase terbesar contoh anak sibuk (36,7\%) memiliki 2 jenis aktivitas dalam satu minggu, sedangkan persentase terbesar anak tidak sibuk $(46,7 \%)$ memiliki 1 jenis aktivitas dalam satu minggu. Rata-rata anak sibuk memiliki 3 jenis aktivitas dan anak tidak sibuk mempunyai 1 jenis aktivitas setiap minggu. Hasil uji beda t-test menunjukkan adanya perbedaan yang sangat nyata $(p<0,01)$ pada variabel jenis kegiatan di luar sekolah contoh dalam satu minggu pada kedua kelompok anak.

Persentase terbesar contoh anak sibuk $(48,4 \%)$ dan lebih dari separuh contoh anak tidak sibuk (56\%) melakukan kegiatan di luar sekolah berdasarkan usulan orang tua.

\section{Persepsi Contoh}

Sebagian besar contoh (78,3\%) memiliki persepsi yang cukup terhadap aktivitas di luar sekolah dan harapan orang tua. Hasil uji beda Mann Whitney menunjukkan tidak adanya perbedaan $(p>0,05)$ pada persepsi contoh terhadap aktivitas di luar sekolah dan harapan orang tua di kedua kelompok (Tabel 1).

\section{Persepsi lbu Contoh}

Persentase terbesar ibu contoh $(73,3 \%)$ memiliki persepsi cukup. Persentase ibu pada kelompok anak sibuk yang berpersepsi baik $(13,3 \%)$ lebih banyak daripada persepsi ibu pada kelompok anak tidak sibuk $(6,7 \%)$ dalam kategori yang sama. Meskipun demikian, hasil uji beda Mann Whitney menunjukkan tidak adanya perbedaan yang nyata pada variabel persepsi ibu diantara kedua kelompok yang diamati (Tabel 2).

Tabel 1. Sebaran contoh menurut kategori persepsi

\begin{tabular}{|c|c|c|c|c|c|c|}
\hline \multirow{2}{*}{ Persepsi contoh } & \multicolumn{2}{|c|}{ Anak sibuk } & \multicolumn{2}{|c|}{ Anak tidak sibuk } & \multicolumn{2}{|c|}{ Total } \\
\hline & $\mathbf{n}$ & $\%$ & $\mathbf{n}$ & $\%$ & $\mathbf{n}$ & $\%$ \\
\hline Kurang & 4 & 13,3 & 2 & 6,7 & 6 & 10,0 \\
\hline Cukup & 23 & 76,7 & 24 & 80,0 & 47 & 78,3 \\
\hline Baik & 3 & 10,0 & 4 & 13,3 & 7 & 11,7 \\
\hline Total & 30 & 100,0 & 30 & 100,0 & 60 & 100,0 \\
\hline Skor min-max & \multicolumn{2}{|c|}{$25-41$} & \multicolumn{2}{|c|}{$26-41$} & \multicolumn{2}{|c|}{$25-41$} \\
\hline Rata-rata $\pm S D$ & \multicolumn{6}{|c|}{$35,03 \pm 3,04$} \\
\hline P-value & \multicolumn{6}{|c|}{0,411} \\
\hline
\end{tabular}


Tabel 2. Sebaran contoh menurut kategori persepsi ibu

\begin{tabular}{|c|c|c|c|c|c|c|}
\hline \multirow{2}{*}{ Persepsi ibu } & \multicolumn{2}{|c|}{ Anak sibuk } & \multicolumn{2}{|c|}{ Anak tidak sibuk } & \multicolumn{2}{|c|}{ Total } \\
\hline & $n$ & $\%$ & $n$ & $\%$ & $\mathrm{n}$ & $\%$ \\
\hline Kurang & 4 & 13,3 & 6 & 20,0 & 10 & 16,7 \\
\hline Cukup & 22 & 73,3 & 22 & 73,3 & 44 & 73,3 \\
\hline Baik & 4 & 13,3 & 2 & 6,7 & 6 & 10,0 \\
\hline Total & 30 & 100,0 & 30 & 100,0 & 60 & 100,0 \\
\hline Skor min-maks & \multicolumn{2}{|c|}{$29-41$} & \multicolumn{2}{|c|}{$26-41$} & \multicolumn{2}{|c|}{$26-41$} \\
\hline Rata-rata $\pm S D$ & \multicolumn{6}{|c|}{$33,90 \pm 2,99$} \\
\hline P-value & \multicolumn{6}{|c|}{0,411} \\
\hline
\end{tabular}

\section{Tingkat Stres}

Gejala stres yang seringkali dialami oleh hampir separuh contoh anak sibuk adalah jantung berdebar kencang dan keras $(46,7 \%)$, merasa sukar berkonsentrasi pada saat melakukan kegiatan $(43,3 \%)$, dan merasa sangat lemas/lesu/tidak memiliki tenaga (43,3\%). Sedangkan gejala stres yang seringkali dialami oleh anak tidak sibuk adalah merasa sukar berkonsentrasi $(43,3 \%$ contoh) dan mengalami mimpi buruk (50\% contoh). Sebaran contoh berdasarkan seringnya mengalami gejala stres dapat dilihat pada Tabel 3 .

Persentase terbesar contoh anak sibuk $(73,3 \%)$ dan anak tidak sibuk $(80,0 \%)$ berada dalam kategori tingkat stres sedang. Tingkat stres sedang memberikan arti bahwa gejala stres kadang-kadang dialami oleh contoh. Persentase anak sibuk yang mengalami tingkat stres yang tinggi $(6,7 \%)$ ternyata lebih sedikit dibandingkan persentase anak tidak sibuk dalam kategori tersebut $(13,3 \%)$. Hasil uji beda Mann Whitney menunjukkan tidak adanya perbedaan $(p>0,05)$ pada variabel tingkat stres di kedua kelompok contoh tersebut.

\section{Hubungan Antar Variabel}

Hubungan antara variabel jenis kelamin dengan aktivitas di luar sekolah diuji dengan menggunakan uji Chi Square. Hasil uji Chi Square menunjukkan adanya hubungan yang nyata antara jenis kelamin contoh dengan jenis $(p=0,02)$ dan alokasi waktu aktivitas di luar sekolah $(p=0,008)$. Semakin meningkatnya jumlah aktivitas dan alokasi waktu kegiatan di luar sekolah, maka persentase contoh yang berjenis kelamin perempuan dalam kategori tersebut semakin banyak.

Selain itu, uji hubungan antara alokasi waktu kegiatan di luar sekolah dengan persepsi anak diamati dengan menggunakan korelasi Spearman. Hasil uji tersebut menunjukkan adanya hubungan yang nyata $(p=0,03, r=-0,281)$ dan negatif antara alokasi waktu kegiatan di luar sekolah dan persepsi anak. Selain itu, tidak terdapat contoh yang memiliki alokasi waktu kegiatan di luar sekolah selama $>1$ jam dalam sehari yang berpersepsi baik.

Sementara itu, hubungan antara persepsi contoh dengan tingkat stres diuji dengan menggunakan uji korelasi Spearman. Hasil uji korelasi tersebut menunjukkan adanya hubungan yang nyata dan negatif antara persepsi contoh dengan tingkat stres $(p=0,021, r=-0,298)$. Selain itu, tidak terdapat contoh dengan tingkat stres rendah yang memiliki persepsi kurang dan tidak terdapat pula contoh dengan persepsi baik yang memiliki tingkat stres tinggi.

\section{Faktor-Faktor Yang Berpengaruh Terhadap Tingkat Stres \\ Dari berbagai variabel yang} tercantum dalam model regresi, yakni umur anak saat masuk SD, jumlah dan alokasi waktu kegiatan di luar sekolah anak, alokasi waktu anak menonton televisi, usia ibu saat anak pertama lahir, pendapatan utama ayah, dan persepsi anak, hanya variabel jumlah aktivitas di luar sekolah dalam satu minggu $(p=0,03)$, alokasi aktivitas di luar sekolah $(p=0,03)$, dan alokasi waktu menonton televisi $(p=0,01)$ yang memiliki pengaruh nyata terhadap tingkat stres contoh.

Nilai adjusted $R$ Square $\left(R^{2}\right)$ dalam model regresi ini adalah sebesar $13,9 \%$. Hal ini berarti bahwa ketujuh variabel diatas hanya dapat menjelaskan 13,9\% dari faktor-faktor yang berpengaruh terhadap tingkat stres yang dialami oleh contoh, selebihnya dijelaskan oleh variabel-variabel yang lain di luar model tersebut, misalnya lingkungan sekolah. 
Tabel 3. Sebaran contoh berdasarkan seringnya mengalami gejala stres

\begin{tabular}{|c|c|c|c|c|c|c|c|}
\hline \multirow{2}{*}{ No, } & \multirow{2}{*}{ Gejala stres } & \multicolumn{2}{|c|}{ Anak Sibuk } & \multicolumn{2}{|c|}{ Anak Tidak Sibuk } & \multicolumn{2}{|c|}{ Total } \\
\hline & & $\mathbf{n}$ & $\%$ & $\mathbf{n}$ & $\%$ & $\mathbf{n}$ & $\%$ \\
\hline 1 & $\begin{array}{l}\text { Merasa pusing/sakit kepala tanpa alasan } \\
\text { yang jelas }\end{array}$ & 2 & 6,7 & 6 & 20,0 & 8 & 13,3 \\
\hline 2 & $\begin{array}{l}\text { Merasa pegal-pegal pada } \\
\text { leher/punggung/bahu }\end{array}$ & 7 & 23,3 & 4 & 13,3 & 11 & 18,3 \\
\hline 3 & $\begin{array}{l}\text { Perut terasa mual/kembung/mulas/diare } \\
\text { pada saat akan melakukan kegiatan } \\
\text { tertentu }\end{array}$ & 4 & 13,3 & 2 & 6,7 & 6 & 10,0 \\
\hline 4 & Mengalami tangan gemetaran & 7 & 23,3 & 2 & 6,7 & 9 & 15,0 \\
\hline 5 & $\begin{array}{l}\text { Sering menjatuhkan/memecahkan } \\
\text { barang/tersandung/terjatuh }\end{array}$ & 6 & 20,0 & 9 & 30,0 & 15 & 25,0 \\
\hline 6 & Jantung berdebar kencang dan keras & 14 & 46,7 & 9 & 30,0 & 23 & 38,3 \\
\hline 7 & $\begin{array}{l}\text { Merasa tidak } \\
\text { tenang/tegang/cemas/terancam }\end{array}$ & 6 & 20,0 & 7 & 23,3 & 13 & 21,7 \\
\hline 8 & $\begin{array}{l}\text { Merasa sukar berkonsentrasi pada saat } \\
\text { melakukan kegiatan }\end{array}$ & 13 & 43,3 & 13 & 43,3 & 26 & 43,3 \\
\hline 9 & $\begin{array}{l}\text { Mengalami sulit tidur/tidak dapat tidur } \\
\text { nyenyak seperti biasanya }\end{array}$ & 5 & 16,7 & 12 & 40,0 & 17 & 28,3 \\
\hline 10 & Mudah tersinggung & 7 & 23,3 & 11 & 36,7 & 18 & 30,0 \\
\hline 11 & Mengalami perubahan nafsu makan & 2 & 6,7 & 4 & 13,3 & 6 & 10,0 \\
\hline 12 & $\begin{array}{l}\text { Merasa sangat lelah/lesu/lemas/tidak } \\
\text { memiliki tenaga }\end{array}$ & 13 & 43,3 & 7 & 23,3 & 20 & 33,3 \\
\hline 13 & $\begin{array}{l}\text { Merasa tidak sabar dan cepat marah tanpa } \\
\text { sebab }\end{array}$ & 2 & 6,7 & 4 & 13,3 & 6 & 10,0 \\
\hline 14 & Merasa tidak memiliki harapan/putus asa & 5 & 16,7 & 4 & 13,3 & 9 & 15,0 \\
\hline 15 & $\begin{array}{l}\text { Merasa bingung/takut bila bertemu dengan } \\
\text { orang lain }\end{array}$ & 6 & 20,0 & 7 & 23,3 & 13 & 21,7 \\
\hline 16 & Merasa sedih sekali dan ingin menangis & 9 & 30,0 & 7 & 23,3 & 16 & 26,7 \\
\hline 17 & $\begin{array}{l}\text { Merasa dipaksa dengan sangat oleh orang } \\
\text { lain (tertekan) }\end{array}$ & 5 & 16,7 & 9 & 30,0 & 14 & 23,3 \\
\hline 18 & Mengalami mimpi buruk & 10 & 33,3 & 15 & 50,0 & 25 & 41,7 \\
\hline
\end{tabular}

\section{KESIMPULAN DAN SARAN}

\section{Kesimpulan}

Karakteristik keluarga contoh menunjukkan status sosial ekonomi yang tinggi. Hal ini ditunjukkan dari pendidikan orang tua yang tinggi (sebagian besar lulusan Perguruan Tinggi) dan juga pendapatan per bulan ayah yang juga tinggi (di atas Rp 7.500.000,00).

Terdapat perbedaan yang nyata pada alokasi waktu aktivitas di luar sekolah pada kedua kelompok contoh. Rata-rata alokasi waktu contoh anak sibuk untuk kegiatan di luar sekolah adalah sebesar 1,12 jam (67 menit) tiap harinya, sedangkan rata-rata alokasi waktu anak tidak sibuk adalah sebesar 0,31 jam (18 menit). Hampir separuh kegiatan contoh di luar sekolah dilakukan berdasarkan usulan orang tua.

Semakin meningkatnya jumlah aktivitas dan alokasi waktu kegiatan di luar sekolah, maka persentase contoh yang berjenis kelamin perempuan dalam kategori tersebut semakin banyak. Semakin meningkat alokasi waktu kegiatan di luar sekolah contoh, maka persepsinya terhadap kegiatan di luar sekolah dan harapan orang tua pada anak akan semakin berkurang. Selain itu, semakin baik persepsi contoh terhadap aktivitas di luar sekolah dan harapan orang tua, maka tingkat stresnya akan semakin menurun.

Penurunan jumlah aktivitas di luar sekolah akan berpengaruh negatif yakni peningkatan stres contoh. Meskipun demikian, peningkatan alokasi waktu 
contoh di luar sekolah akan meningkatkan tingkat stres. Peningkatan alokasi waktu menonton televisi akan menurunkan tingkat stres.

\section{Saran}

Hasil penelitian menunjukkan bahwa alokasi waktu berhubungan negatif dengan persepsi anak, oleh karena itu aktivitas di luar sekolah anak sebaiknya beragam jenisnya dan tidak dilakukan lebih dari satu jam setiap harinya. Sebelum menganjurkan untuk melakukan kegiatan di luar sekolah, sebaiknya orang tua menumbuhkan persepsi yang positif dalam diri anak terhadap kegiatan yang akan dilakukannya tersebut, diantaranya adalah dengan jalan memaparkan manfaat kegiatan tersebut bagi anak (menyalurkan hobi, menambah teman, dan sebagainya). Meskipun demikian orang tua tidak diperbolehkan menekan atau memaksa anak untuk mengikuti kegiatan di luar sekolah. Hasil penelitian juga memperlihatkan bahwa menonton televisi merupakan salah satu kegiatan

\footnotetext{
*Korespondensi :

Departemen IImu Keluarga dan Konsumen

Fakutas Ekologi Manusia IPB

Jl. Lingkar Kampus IPB Dramaga 16680

Telp : +62-251 8628303

Email: diahkp@yahoo.com
}

yang dapat mengurangi stres anak. Karena itu, tidak apa-apa memberikan kesempatan pada anak untuk menonton televisi. Meskipun demikian, orang tua sebaiknya mendampingi anak dalam menonton televisi untuk memberikan arahan mengenai tayangan televisi dan supaya anak tidak terlalu lama menonton televisi.

\section{DAFTAR PUSTAKA}

Alvin NG. 2007. Handling Study Stress. Jakarta: PT Elex Media Komputindo.

Gross G. tt. Are your giving your kids hurried child syndrome?. http://www. naturalfamilyonline.com/5-ap/46-

hurried-child.htm. [25 Desember 2007].

Hurlock E. 2002. Perkembangan Anak. Meitasari T, Muslich Z, penerjemah. Ed ke-6. Jakarta: Penerbit Erlangga.

Imam S. 15 Desember 2007. Sekolah, sumber stres anak. Nakita: 14 . 